\title{
Morphospace saturation in the stem-gnathostomes pteraspidiformes heterostracans: an early radiation of a 'bottom' heavy clade
}

\author{
Marco Romano $^{\text {Corresp.. }}{ }^{1}$, Robert Sansom ${ }^{2}$, Emma Randle ${ }^{2}$ \\ 1 Evolutionary Studies Institute (ESI), School of Geosciences, University of the Witwatersrand, Johannesburg, South Africa \\ 2 School of Earth and Environmental Sciences, University of Manchester, Manchester, United Kingdom \\ Corresponding Author: Marco Romano \\ Email address: marco.romano@uniroma1.it
}

Ostracoderms (fossil armoured jawless fishes) shed light on early vertebrate evolution by revealing the step-wise acquisition of jawed vertebrate characters, and were important constituents of Middle Palaeozoic vertebrate faunas. A wide variety of head shield shapes are observed within and between the ostracoderm groups, but the timing of these diversifications and the consistency between different measures of their morphospace are unclear. Here, we present the first disparity (explored morphospace) versus diversity (number of taxa) analysis of Pteraspidiformes heterostracans using continuous and discrete characters. Patterns of taxic diversity and morphological disparity are in accordance: they both show a rise to a peak in the Lochkovian followed by a gradual decline in the Middle-Late Devonian. Patterns are largely consistent for disparity measures using sum of ranges or total variance, and when using continuous or discrete characters. Pteraspidiformes heterostracans can be classified as a "bottom-heavy clade", i.e. a group where a high initial disparity decreasing over time is detected. In fact, the group explored morphospace early in its evolutionary history, with much of the subsequent variation in dermal armour occurring as variation in the proportions of already evolved anatomical features. This Early Devonian radiation is also in agreement with the paleobiogeographic distribution of the group, with a maximum of dispersal and explored morphospace during the Lochkovian and Pragian time bins. 
3

4

\section{Morphospace saturation in the stem-gnathostome pteraspidiformes} heterostracans: an early radiation of a 'bottom' heavy clade

3

4

5

6

7 Witwatersrand, Johannesburg, South Africa; ${ }^{2}$ School of Earth and Environmental Sciences,

8


*corresponding author: marco.romano@uniromal.it

\section{ABSTRACT}

Ostracoderms (fossil armoured jawless fishes) shed light on early vertebrate evolution by revealing the step-wise acquisition of jawed vertebrate characters, and were important constituents of Middle Palaeozoic vertebrate faunas. A wide variety of head shield shapes are observed within and between the ostracoderm groups, but the timing of these diversifications and the consistency between different measures of their morphospace are unclear. Here, we present the first disparity (explored morphospace) versus diversity (number of taxa) analysis of Pteraspidiformes heterostracans using continuous and discrete characters. Patterns of taxic diversity and morphological disparity are in accordance: they both show a rise to a peak in the Lochkovian followed by a gradual decline in the Middle-Late Devonian. Patterns are largely consistent for disparity measures using sum of ranges or total variance, and when using continuous or discrete characters. Pteraspidiformes heterostracans can be classified as a "bottomheavy clade", i.e. a group where a high initial disparity decreasing over time is detected. In fact, the group explored morphospace early in its evolutionary history, with much of the subsequent variation in dermal armour occurring as variation in the proportions of already evolved anatomical features. This Early Devonian radiation is also in agreement with the paleobiogeographic distribution of the group, with a maximum of dispersal and explored morphospace during the Lochkovian and Pragian time bins. 


\section{INTRODUCTION}

Ostracoderms (extinct, bony jawless vertebrates) are a paraphyletic assemblage comprising

the jawed vertebrate stem group, which dominated the early vertebrate assemblages, first

appearing with high levels of diversity in the Silurian (Sansom, Randle \& Donoghue, 2015).

Seen within the ostracoderms are many novel vertebrate features such as the first appearance of mineralised bone, paired appendages and paired sensory organs (Donoghue \& Keating, 2014). The diversity of headshield shapes is large, with many groups variously possessing lateral,

58 anterior and dorsal processes. The timing and nature of these morphological diversifications is unclear, as is the best way to quantify the morphological variation. For example, the difficulty in taxonomic assignment and phylogenetic reconstruction of the Pteraspidiformes (the largest clade of heterostracan ostracoderms) can be attributed to the continuous variation in their dermal plates which is often used to discriminate between taxonomic grades (Ilyes \& Elliott, 1994; Pernègre, 2002; Pernègre \& Goujet, 2007; Pernègre \& Elliott, 2008; Randle \& Sansom, 2017a; Randle \& Sansom, 2017b). The Pteraspidiformes are characterised by possessing separate dorsal, ventral, rostral and pineal plates along with paired branchial, orbital and in some instances cornual plates (Fig. 1D)(Blieck, 1984; Blieck, Elliott \& Gagnier, 1991; Janvier, 1996; Pernègre \& Elliott, 2008; Randle \& Sansom, 2017a; Randle \& Sansom, 2017b). The Pteraspidiformes include many families and taxa of uncertain affinities. The Anchipteraspididae and Protopteraspis are 
stratigraphically the oldest Pteraspidiformes first occurring in the Pridoli (Elliott 1983; Blieck 1984; Blieck \& Tarrant 2001). The Anchipteraspididae and Protopteraspis are both small Pteraspidiformes with blunt shaped rostra (Fig. 1E). The Anchipteraspididae have a few anatomical differences to the remaining Pteraspidiformes including; a pineal plate enclosed within their dorsal plate, rather than positioned between the rostral and dorsal plates as seen in all other Pteraspidiformes, a fused orbito-cornual plate (with are completely separate in other Pteraspidiformes taxa) and the centre of growth in the dorsal plate anterior to the midline, whereas, in other forms it is centrally or posteriorly positioned (Randle \& Sansom 2017a; Elliott 1983). Other families include the Rhinopteraspididae (Fig. 1E), which contains taxa with extremely lengthened rostra and headshields e.g. Rhinopteraspis and Althaspis, the Protaspididae, which contains taxa with widened headshields and forms with posteriorly extended branchial plates and absent cornual plates, and finally the Doryaspididae, containing the enigmatic Doryaspis, which has an unusually dorsally orientated mouth, extreme laterally extended cornual plates and a unique pseudorostum (White 1935; Janvier 1996; Pernègre 2002). Randle \& Sansom (2017a) also found the two Psammosteidae taxa to be nested within the Pteraspidiformes. The Psammosteidae are stratigraphically the youngest heterostracans and are characterised by having a dorsally orientated mouth and small 'platelets' separating their major plates (Blieck 1984; Janvier 1996)(Fig. 1E).

Due to the Pteraspidiformes possessing a rather uniform anatomy, inclusion of taxonomically informative quantitative data, including the relative sizes and dimensions of dermal plates, was explored in the phylogenetic analyses of Randle \& Sansom (2017a), who included two different treatments of quantitative ratio data in their phylogenetic analyses of the Pteraspidiformes. The first treatment discretised the quantitative data into ordinal discrete 
92 character states by identifying gaps between the differences of ordered ratio data $(>2$ standard 93 deviations of the gap data) to infer changes in character states. The second treatment used the

94 raw continuous quantitative data to reconstruct their evolutionary relationships. Inclusion of

95 quantitative data greatly improved the resolution of Pteraspidiformes relationships using

96 traditional discrete characters - however, the two methods provided different and conflicting

97 evolutionary relationships.

98 One of the goals of this study is to explore morphospace occupation through time using both

99 classic discrete cladistic characters and quantitative continuous characters, along with the signal

100 these phylogenetic morphospace plots provide for the different taxonomic clades within the

101 Pteraspidiformes.

102 The use of cladistic or more traditional morphometric characters is debated in macro-

103 evolution fields with authors arguing that discrete and morphometric characters differ in relative

104 degree of independence, homology of the considered features, their rates of evolution and on the 105 nature of the variation being captured (MacLeod 2002; Klingenberg \& Gidaszewski 2010).

106 Mongiardino Koch et al. (2017) when exploring the scorpion genus Brachistosternus using

107 morphospaces derived from discrete and morphometric characters, found the signal derived from

108 these two different data types to be significantly different from each providing a non-congruent

109 picture of their early evolution. For example, their discrete data displayed an 'early burst'

110 scenario, whereas their morphological data did not, which they concluded was due to evolution

111 being driven by species-specific adaptations of morphometric traits. On the contrary, several

112 studies have shown empirically how the results derived from discrete and morphometric

113 characters are fully compatible, providing the same signal on a macro-evolutionary scale (e.g.

114 Villier \& Eble, 2004; Anderson \& Friedman, 2012; Foth et al., 2012; Hetherington et al., 2015; 
115 Romano et al., 2017). In particular, Villier and Eble (2004) were the first to empirically

116 demonstrate that disparity calculated using morphometric measures and discrete characters

117 converge to the same signal, using the echinoid order Spatangoida as case study. As a general

118 conclusion, the authors stressed how the choice of different morphometric scheme temporal

119 scale, and taxonomic level seems to no affect major macroevolutionary trendin disparity.

120 Foth et al. (2012) demonstrate as in the Mesozoic fossil reptile clade Pterosauria, different

121 proxy for cranial disparity (landmark-based geometric morphometrics, limb proportion datasets

122 and classic discrete characters) converge to the same macroevolutionary signal. Thus, according

123 to the authors, all such different approaches in the end testify a congruent pattern of

124 morphospace evolution in pterosaurs. As stressed by the authors such results are very

125 encouraging, since in several ease just one of the several proxy is available to conduct disparity

126 analyses in fossil clades.

127 In an exploratory study of disparity focusing on caecilian amphibians, Hetherington et al.

128 (2015) found no impact on relative inter taxon distances when different coding strategies for

129 cladistics characters were considered or by taking in consideration revised concepts of

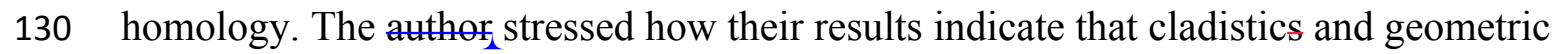

131 morphometric data seem to carry the same disparity signal, thus summarizing in comparable

132 ways the morphological variation for the clade. The authors in conclusion strongly supported the

133 cladistics dataset as source to calculate and characterize clade disparity.

134 Romano et al. (2017) empirically show in captorhinids, disparity calculated using

135 cladistic discrete character and continuous morphometric character ${ }_{2}$ converge to the same

136 macroevolutonary signal through the whole evolutionary history of the group. Interestingly,

137 while the discrete dataset is built essentially on classical cranial characters, the morphometric 
138 ones is based almost totally on long bones. As already stressed by Foth et al. (2012), alse in this

139 case the empirical study shows that, in the absence of one of the possible proxies, the disparity

140 calculated based on just one type of characters can be considered representative of the disparity

141 pattern on a large macroevolutionary scale.

142 In discussing to what extent the conclusions obtained from their particular study on caecilian

143 amphibians were generalizable, Hetherington et al. (2015) strongly encouraged similar studies on

144 other clades, both of invertebrates and vertebrates. In this framework, the specific clade of

145 Pteraspidiformes therefore represents a new interesting case to empirically test the possible

146 congruence between the signals contained in the discrete and morphometric characters.

147 Important in this context is whether timing of morphospace occupations as either early or

148 late in the history of a clade and how they compare to changes in taxic diversity. Studies of

149 morphospace occupation in both invertebrates (e.g. Foote, 1994, 1999; Lofgren, Plotnick, \&

150 Wagner, 2003; Villier \& Eble, 2004; Lefebvre et al., 2006; Al-Sabouni, Kucera, \& Schmidt, 151 2007; Scholz \& Hartman, 2007; Glaubrecht, Brinkmann, \& Pöppe, 2009; Whiteside \& Ward,

152 2011; Deline \& Ausich, 2011; Bapst et al., 2012; Hopkins, 2013; Romano et al., 2018) and

153 vertebrates (e. g. Prentice, Ruta, \& Benton, 2011; Benson, Evans, \& Druckenmiller, 2012; Ruta

154 et al., 2013; Colombo et al., 2015; Marx \& Fordyce, 2015; Larson, Brown, \& Evans, 2016;

155 Romano, 2017; Romano et al., 2017) have reconstructed the timing of radiations, with many

156 identifying maximum disparity at the beginning of their evolutionary history (termed 'bottom

157 heavy'), followed by stabilization and constant decrease until their subsequent extinction (e.g.

158 Gould, Gilinsky, \& German, 1987; Foote, 1992, 1994, 1995, 1999; McGhee, 1995; Wagner,

159 1995; Smith \& Bunje, 1999; Eble, 2000; Huntley, Xiao, \& Kowalewski, 2006; Ruta et al., 2013;

160 Marx \& Fordyce, 2015; Romano, 2017). Here we test the timing of morphospace radiations for 
161 Pteraspiformes and compare that to taxic diversity. We compare total variance or as a sum of

162 ranges as measures of disparity, in both discrete and continuous sub-datasets.

163

164

165

166

167

168

169

170

171

172

173

174

175

176

177

178

179

180

181

182

\section{MATERIAL AND METHODS}

\section{Taxa}

The analysis was conducted using the phylogenetic analysis dataset of Pteraspidiformes heterostracans recently published by Randle \& Sansom (2017a). For the study only the 49 ingroup taxa of the original dataset were considered as follows: Alaeckaspis, Althaspis, Anchipteraspis, Blieckaspis, Brachipteraspis, Canadapteraspis, Cosmaspis, Cyrtaspidichthys, Djurinaspis, Dnestraspis, Doryaspis, Drepanaspis, Errivaspis, Escharaspis, Eucyclaspis, Europrotaspis, Gigantaspis, Helaspis, Lamiaspis, Lampraspis, Larnovaspis, Loricopteraspis, Miltaspis, Mylopteraspis, Mylopteraspidella, Oreaspis, Palanasaspis, Panamintaspis, Parapteraspis, Pavloaspis, Pirumaspis, Podolaspis, Protaspis, Protopteraspis gosseleti, Protopteraspis primaeva, Psammosteus, Psephaspis, Pteraspis, Rachiaspis, Rhinopteraspis, Semipodolaspis, Stegobranchiaspis, Tuberculaspis, Ulutitaspis, Unarkaspis, Woodfjordaspis, Xylaspis, Zascinaspis carmani, Zascinaspis heintzi. The taxa Anglaspis, Athenaegis and Nahanniaspis chosen as outgroups by Randle and Sansom (2017a) were not considered for the study of diversity and disparities through time. Thus, apart from the four species Protopteraspis gosseleti, Protopteraspis primaeva, Zascinaspis carmani and Zascinaspis heintzi, the majority of taxa are considered at the genus level. Foote $(1995,1996)$ has empirically shown how analysis 
183 conducted at the species and genus level provide equivalent signal (however Smith \&

184 Lieberman, 1999 consider the species level as preferable).

185

186

187

188

189

190

191

192

193

194

195

196

197

198

199

200

201

202

203

204

205

\section{Diversity and disparity}

To perform the analysis the following six time bins were selected spanning from the Upper Silurian to the Upper Devonian: Pridoli, Lochkovian, Pragian, Emsian, Eifelian, GivetianFrasnian. The Givetian and Frasnian stages were considered in a single time bin, since for the analysis of the disparity at least two taxa must be present in each considered interval. The distribution of taxa in the different time bins was based on the time calibrated tree of Pteraspidiformes heterostracans provided by Randle \& Sansom (2017a, p. 595, fig. 7); the occurrence of taxa for each time bins is reported in supplementary material (Appendix 1).

Taxic diversity for Pteraspidiformes heterostracans is simply the sum of taxa in each time bin. Two disparity analyses were conducted; one on the classical discrete characters and the second, using the continuous characters only. Disparity was calculated both as the total variance and as the sum of ranges for the two different datasets (discrete and continuous). According to several authors (Foote, 1997; Erwin, 2007; Ruta, 2009; Prentice, Ruta, \& Benton, 2011) disparity as total variance indicates essentially how the considered taxa are dispersed in the morphospace, whereas disparity as sum of ranges represents a good indication of the total occupied morphospace through time (see Wills, Briggs, \& Fortey, 1994; Prentice, Ruta, \& Benton, 2011). These indications must be carefully taken into account in the interpretation of the results obtained with the study (see below).

Disparity analysis of the discrete dataset (65 discrete characters, see Appendix 2) (Randle \& Sansom, 2017a) was subjected to a Principal Coordinates Analysis on the free software PAST 
206

207

208

209

210

211

212

213

214

215

216

217

218

219

220

221

222

223

224

225

226

227

228

3.10 (Hammer, Harper, \& Ryan 2001), using the 'Gower' similarity index (c=2 Transformation Exponent), preferable to the simple Euclidean distance (see Hammer, 2013). Coding for the discreet character 42 in Helaspis and Psephaspis has been replaced by a question mark being polymorphic in the two taxa (two states of the character present). The PCO scores were used to calculate disparity, both as total variance and as sum of ranges, for the discrete character dataset (see Appendix 1 in the supplementary material). Only the first 23 principal coordinates were considered in the results, as the 24 th was constant, not contributing to disparity.

22 continuous characters from Randle and Sansom (2017a; see Appendix 2) were analysed using a Principal Component Analysis, again using the software PAST 3.10. Missing entries were computed using the 'iterative imputation' in PAST, as suggested by Hammer (2013). Before the analysis, the raw data were log transformed for the correspondence of the logtransform to an isometric null hypothesis and to fit linear models (see Chinnery, 2004; Cheng et al., 2009; Romano \& Citton, 2015; Romano \& Citton, 2017; Romano, 2017a; Romano,2017b; Citton et al., 2017). Linear measures are in general preferable to ratios in Principal Component Analyses (see Hammer and Harper, 2006). However in this case the original ratios were used to perform the analysis, to be congruent with the results obtained by Randle \& Sansom (2017a).

Even in this case, the scores obtained from the 22 principal components were used to calculate disparity both as sum of ranges and variance (see Appendix 1).

\section{RESULTS}

The first occurrence of Pteraspidiformes heterostracans is in the Pridoli (Upper Silurian) with fairly low levels of diversity (Figs. 2A), and the clade is represented by just 4 genera. However, their diversity rises and attains its maximum in the Lochkovian to Pragian. From the 
229 Emsian onwards the number of taxa begins to decrease consistently until their demise in the

230 Frasnian (Upper Devonian).

231 Disparity for the discrete characters (Fig. 2B) follow a very similar pattern to diversity,

232 especially the sum of ranges. Disparity, as measured by total variance, begins to decrease in the

233 Pragian, while the sum of ranges disparity remains at the same level of the preceding time bin

234 (i.e. Lochkovian). Sum of ranges disparity begins to decline from the Emsian onwards mirroring

235 that of diversity; however, disparity as total variance shows the same value for the Emsian and

236 Eifelian after which it decreases abruptly until it reaches the minimum in the Givetian-Frasnian.

237 Similarly to the discrete characters the trend of disparity as sum of ranges for the continuous

238 characters (Fig. 2C), closely matches the diversity through time except for a peak in the Pragian.

239 Contrasting with the discrete characters, the continuous characters have high levels of disparity

240 (for both sum of ranges and total variance) in the Pridoli. Disparity as total variance is decoupled

241 with respect to diversity, with maximum disparity occurring at the beginning of their

242 evolutionary history rather than in the Lochkovian, as seen in the discrete characters disparity.

243 After this initial peak in the Pridoli, disparity declines until the Pragian and remains low until

244 Givetian-Frasnian.

245 Morphospace occupation for the discrete characters and continuous characters through time

246 can be seen in Fig. 3A. Maximum morphospace exploration (convex hull area) for the discrete

247 characters is observed in the Lochkovian, which overlaps with morphospace occupied by

248 Pteraspidiformes in the Pridoli and subsequent time bins (Pragian-Frasnian). Fig. 3B shows

249 morphospace occupation of Pteraspidiformes as described by the continuous characters. There

250 appears much more overlap in morphospace occupation through time bins than seen in the 
251 discrete characters, with one taxon extending morphospace occupation in the Pridoli. Throughout

252 the majority of their history the Pteraspidiformes, occupy similar morphospace.

253 Fig. 4 shows the relative position of Pteraspidiformes taxa, grouped by family, in their

254 Principal component analyses (continuous characters) and Principal coordinates (discrete

255 characters) using the first two axes. There is much overlap in Pteraspidiformes morphospace

256 using the continuous characters (Fig. 4A), whereas, the discrete morphospace plot (Fig. 4B) there

257 is much less overlap between the taxonomic groups. In particular, the Doryaspidae and

258 Anchipteraspididae are very well separated, without overlap from the convex hulls of other

259 families in the continuous character plot.

260 Other patterns seen in the classic cladistic character plot (Fig. 4A) includes the

261 Protopteraspididae overalpping with all the other convex hulls, with a truly substantial

262 superimposition with the Anchipteraspididae, which in this case are not well separated from

263 morphospaces explored by other groups. Another interesting result is that members of

264 Psammosteidae do not cluster together in the graph, with Psammosteus occurring completely

265 within the morphospace of the Doryaspidae. Many Pteraspidoidei incertae sedis fall within the

266 convex hull identified by the families recognized by Randle \& Sansom (2017a); the only taxa

267 that fall outside a convex hull or the overlapping of several convex hulls are Eucyclaspis,

268 Parapteraspis, and Podolaspis.

269 The scatter plot of the PCA conducted on discrete characters is shown in Fig. 4B. patterns

270 include overlap between the Rhinopteraspididae and Protopteraspididae, with Althaspis

271 occurring in the shared morphospace. A second overlap in morphospace occupation is observed

272 in the ranges of Protaspididae and Protopteraspididae, with Tuberculaspis and Lampraspis

273 falling well inside the morphospace of Protopteraspididae. Among the Pteraspidoidei incertae 
274 sedis, the taxa Djurinaspis, Dnestraspis, Europrotaspis, Lamiaspis, Larnovaspis, Oreaspis,

275 Pteraspis Semipodolaspis and Unarkaspis are not included in any convex hull identified by the

276 PCA; Mylopteraspis, Eucyclaspis fall within the Protaspididae; Alaeckaspis, Blieckaspis,

277 Eucyclaspis, Mylopteraspidella, and Protaspis fall within the morphospace of

278 Protopteraspididae; Parapteraspis and Pirumaspis fall within the convex hull identified by the

279 Rhinopteraspididae. Compared to the result obtained with the continuous characters (Principal

280 Component Analysis), a greater and substantial separation is evident among the families of

281 Pteraspidiformes in morphospace.

282

283

284

285

286

287

288

289

290

291

292

293

294

295

\section{DISCUSSION}

Diversity-disparity curves show that the disparity as sum of the ranges and total variance provide completely compatible and mostly superimposable macroevolution trends for classical discrete characters (Figs. 2), whereas for the continuous ones the trend detected by the total variance results quite different. Considering total variance as a measure of the dispersion of taxa (Foote, 1997; Erwin, 2007; Ruta, 2009; Prentice, Ruta, \& Benton, 2011), the result shows that for the continuous characters the maximum dispersion in the morphospace is found at the beginning of Pteraspidiformes evolutionary history (during the Pridoli); the dispersion then decreased consistently from the Lochkovian onwards. A possible explanation for this trend in the total variance could be the 'early burst' scenario. Mongiardino Koch et al. (2017) suggest that an 'early burst' result can be spurious if obtained from cladistic discrete characters as these are biased towards obviating autapomorphic characters overestimating evolution at the base of a clade. We, however, identify this pattern in our continuous dataset, perhaps suggesting that any 
296

297

298

299

300

301

302

303

304

305

306

307

308

309

310

311

312

313

314

315

316

317 318

generalization must be taken with caution, and that different clades can react differently and peculiarly to disparity analysis.

For all the above, worthy of note is a brief discussion on the reliability of using classical discrete cladistic characters to investigate disparity trend in a clade. Anderson \& Friedman (2012), on the base of an empirical study on early gnathostomes, highlighted possible inconsistencies between the signals obtained from discrete and morphometric characters. In particular, according to the authors, the biggest issue with cladistics characters for disparity analyses derives from the exclusion of autapomorphies from the original matrix (as not informative for phylogeny), and of potentially undersampling 'noisy' homoplastic features. These elements could obviously lead to the loss of information to reconstruct the total morphospace of a group during its evolutionary history. However, the inconsistency of the results obtained on early gnathostomes by Anderson \& Friedman (2012) is strictly related to specific functional variation in the clade, and not to the overall morphological disparity. In fact the authors consider in general the disparity based on cladistics characters as "an important and broadly applicable tool for quantitative paleobiological analyses" (Anderson \& Friedman, 2012, p. 1262), even if not really suitable for ecological and functional variation analyses. The same authors stressed how disparity analyses conducted on cladistic dataset will in any case be characterized by a cladistic signal that needs to be acknowledged when they are used. However, the fact that our analysis is not focused on a specific functional structure or ecological variation but on overall morphospace of the group, and considering that discrete and morphometric characters converge to the same macro-evolutionary signal (using the sum of ranges as indication of morphospace saturation), we are very confident about the soundness and solidity of the results obtained in the present contribution. In any case, in the interpretation of the results in the present paper, and in 
319 numerous other contributions based on cladistic characters, we must bear in mind that several

320 homoplastic characters, autapomorphies and background 'morphological noise' will be missing

321 from cladistic datasets, so most probably underestimating the 'total disparity' for a clade

322 (however in the dataset used in the present contribution some autapomorphies are considered, i.e.

323 character 4 in Djurinaspis, characters 22 and 58 in Doryaspis, character 52 in Miltaspis,

324 character 60 in Lamiaspis). It follows, that part of the original biological variation, expressed as

325 disparity, will be missing from the cladistics dataset analyses. However, Hetherington et al.

326 (2015) even obtaining the same large scale trend in disparity from discrete and morphometric

327 characters, strongly prefer discrete cladistics character data since "in addition to encompassing

328 the gain and loss of structures, they readily allow all aspects of organismal biology to be

329 captured, as opposed to morphometrics which, for entirely practical reasons, is invariably only

330 ever applied to proxy components of anatomy" (Hetherington et al., (2015, p. 398).

331 The results in general indicate that Pteraspidiformes heterostracans explored morphospace

332 early in their evolutionary history (Pridoli-Lochkovian), with much of the subsequent variation

333 in their dermal armour occurring as variation in the proportions of already evolved anatomical

334 features (Fig.2 \& 3). Considering the total variance as a measure of the dispersion of the taxa in

335 morphospace (see Foote, 1997; Erwin, 2007; Ruta, 2009; Prentice, Ruta, \& Benton, 2011) and

336 the sum of ranges as an indication of the total occupied morphospace (see Wills, Briggs, \&

337 Fortey, 1994; Prentice, Ruta, \& Benton, 2011), the results also indicate that the Pteraspidiformes

338 increase in taxonomic diversity also corresponds to an increase in taxa dispersion in

339 morphospace and morphologies. This is followed by a progressive decrease in taxic diversity and

340 morphospace occupation from the Emsian until their demise in the Frasnian (Fig. 2). 
347 blastozoans (Foote, 1992), brachiopods (Carlson, 1992; McGhee, 1995; Smith \& Bunje, 1999),

348 Neoproterozoic acritarchs (Huntley, Xiao, \& Kowalewski, 2006), Palaeozoic gastropods

349 (Wagner, 1995), and crinoids (Foote, 1994, 1995, 1999). In the same way, a decrease in occupied and Palaeozoic stenolaemate bryozoans (Anstey \& Pachut, 1995).

The discrete and continuous characters display differing patterns of overall morphospace occupation for the different taxonomic groups (Fig. 4). The continuous characters displays much overlap of taxonomic groups in morphospace, whereas, the discrete dataset show separate morphospace occupation for the families recognized by Randle \& Sansom (2017a), apart from a slight overlap in the convex hulls of Protaspididae and Protopteraspididae, and between

358 Protopteraspididae and Rhinopteraspididae.

\section{CONCLUSIONS}

361 In this paper we present the first disparity (explored morphospace) versus diversity (number of taxa) analysis of Pteraspidiformes heterostracans using continuous and discrete characters. 
363 Patterns of morphological disparity and taxic diversity are in accordance, both showing a rise to

364 a peak in the Lochkovian followed by a gradual decline in the Middle-Late Devonian.

365 The Pteraspidiformes, unlike other groups of heterostracans (i.e. Cyathaspididae and

366 Traquairaspididae) arose later in the evolutionary history of the Heterostraci (the first

367 heterostracans are from the Wenlock) (Randle \& Sansom, 2017a; Ball \& Dineley, 1963; Dineley

$368 \&$ Loeffler, 1976). Therefore, it is unlikely that the early history of the Pteraspidiformes clade is

369 lost due to fossil record or other abiotic biases, such as sea-level, as seen with other ostracoderm

370 clades (Sansom, Randle \& Donoghue, 2015). There is good correspondence between maximum

371 taxonomic diversity and saturation of occupied morphospace, identifying the Pteraspidiformes

372 heterostracans as a 'bottom' heavy clade, with most structural 'bauplans' and major

373 morphologies already explored by the group in the Early Devonian.

374

\section{ACKNOWLEDGEMENTS}

376 We would like thank museum staff for access to specimens, the Editor and two anonymous 377 reviewers who greatly improved the manuscript.

378

379

380

381

382

383

\section{REFERENCES}

Al-Sabouni N, Kucera M, Schmidt DN. 2007. Vertical niche separation control of diversity and size disparity in planktonic foraminifera. Marine Micropaleontology 63:75-90.

Anderson PS, Friedman M. 2012. Using cladistic characters to predict functional variety: experiments using early gnathostomes. Journal of Vertebrate Paleontology 32: 1254-1270. 
384 385

386

387

388

389

390

391

392

393

394

395

396

397

398

399

400

401

402

403

404

405

Anstey AL, Pachut JF. 1995. Phylogeny, diversity history and speciation in Paleozoic bryozoans. 239-284. In Erwin, D. H. and Anstey, A. L. (eds). New approaches to speciation in the fossil record. Columbia University Press, New York, NY, 288 pp.

Bapst DW, Bullock PC, Melchin MJ, Sheets HD, Mitchell CE. 2012. Graptoloid diversity and disparity became decoupled during the Ordovician mass extinction. Proceedings of the National Academy of Sciences 109: 3428-3433.

Benson RB, Evans M, Druckenmiller PS. 2012. High diversity, low disparity and small body size in plesiosaurs (Reptilia, Sauropterygia) from the Triassic-Jurassic boundary. PLoS One 7: e31838.

Blieck ARM. 1984. Les Heterostraces Pteraspidiformes: systemastique, phylogenie, biostratigraphie et biogeographie. Cahiers de Paléontologie, 1-205.

Blieck ARM, Elliott DK, Gagnier PY. 1991. Some questions concerning the phylogenetic relationships of heterostracans, Ordovician to Devonian jawless vertebrates. In: Mee-Mann C, Yu-hai L, Zhang G eds. Early vertebrates and related problems of evoltionary biology (Intern. Symp. Beijing, 1987). Beijing: Science Press, 1-17.

Blieck ARM, Tarrant PR. 2001. Protopteraspis gosseleti (Vertebrata: Pteraspidimorphi: Heterostraci) from the Lower Devonian of Shropshire, England. Palaeontology 44: 95-112.

Carlson SJ. 1992. Evolutionary trends in the articulate brachiopod hinge mechanism. Paleobiology 18(3):344-366.

Cheng YN, Holmes R, Wu XC, Alfonso N. 2009. Sexual dimorphism and life history of Keichousaurus hui (Reptilia: Sauropterygia). Journal of Vertebrate Paleontology 29:401408. 
406 Chinnery B. 2004. Morphometric analysis of evolutionary trends in the ceratopsian postcranial 407 skeleton. Journal of Vertebrate Paleontology 24:591-609.

408 Citton P, Romano M, Salvador I, Avanzini M. 2017. Reviewing the upper Pleistocene human 409 footprints from the 'Sala dei Misteri'in the Grotta della Bàsura (Toirano, northern Italy) cave: An integrated morphometric and morpho-classificatory approach. Quaternary Science Review 169:50-64.

Colombo M, Damerau M, Hanel R, Salzburger W, Matschiner M. 2015. Diversity and disparity

Davis SP, Finarelli JA, Coates MI. 2012. Acanthodes and shark like conditions in the last through time in the adaptive radiation of Antarctic notothenioid fishes. Journal of Proceedings of the National Academy of Sciences 89:7325-7329.

Foote M. 1994. Morphological disparity in Ordovician-Devonian crinoids and the early saturation of morphological space. Paleobiology 20:320-344. 
429 Foote M. 1995. Morphology of Carboniferous and Permian crinoids. Contributions from the $430 \quad$ Museum of Paleontology, University of Michigan 29:135-184.

431 Foote M. 1996. Ecological controls on the evolutionary recovery of post-Paleozoic crinoids.

$432 \quad$ Science 274: 1492-1495.

433 Foote M. 1997. Sampling, taxonomic description, and our evolving knowledge of morphological 434 diversity. Paleobiology 23:181-206.

435 Foote M. 1999. Morphological diversity in the evolutionary radiation of Paleozoic and post436 Paleozoic crinoids. Paleobiology 25:1-116.

437 Foth C, Brusatte S, Butler R. 2012. Do different disparity proxies converge on a common signal? 438 Insights from the cranial morphometrics and evolutionary history of Pterosauria (Diapsida: 439 Archosauria). Journal of evolutionary biology 25: 904-915.

440 Glaubrecht M, Brinkmann N, Pöppe J. 2009. Diversity and disparity 'down under': Systematics, 441 biogeography and reproductive modes of the 'marsupial'freshwater Thiaridae 442 (Caenogastropoda, Cerithioidea) in Australia. Zoosystematics and Evolution 85:199-275. 443 Gould SJ, Gilinsky NL, German RZ. 1987. Asymmetry of lineages and the direction of 444 evolutionary time. Science 236:1437-1441.

Halliday TJD, Goswami A. 2016. Eutherian morphological disparity across the end-Cretaceous 446 mass extinction. Biological Journal of the Linnean Society 118:152-168.

447 Hammer Ø. 2013. PAST Paleontological Statistics Version 3.0: Reference Manual. University of $448 \quad$ Oslo.

449 Hammer Ø, Harper DAT, Ryan PD. 2001. PAST: paleontological statistics software package for $450 \quad$ education and data analysis. Palaeontol Electron 4, 9. 
451 Hetherington AJ, Sherratt E, Ruta M, Wilkinson M, Deline B., Donoghue PCJ. 2015. Do

$452 \quad$ cladistic and morphometric data capture common patterns of morphological disparity?

$453 \quad$ Palaeontology 58: 393-399.

454 Hopkins MJ. 2013. Decoupling of taxonomic diversity and morphological disparity during

455 decline of the Cambrian trilobite family Pterocephaliidae. Journal of Evolutionary Biology

$456 \quad 26: 1665-1676$.

457 Huntley JW, Xiao SH, Kowalewski M. 2006. 1.3 billion years of acritarch history: an empirical 458 morphospace approach. Precambrian Research 144:52-68.

459 Klingenberg CP, Gidaszewski NA. 2010. Testing and quantifying phylogenetic signals and 460 homoplasy in morphometric data. Systematic Biology 59: 245-261.

461 Janvier P. 1996. Early Vertebrates. New York: Oxford University Press Inc.

462 Larson DW, Brown CM, Evans DC. 2016. Dental disparity and ecological stability in bird-like 463 dinosaurs prior to the end-Cretaceous mass extinction. Current Biology 26:1325-1333.

464 Lefebvre B, Eble GJ, Navarro N, David B. 2006. Diversification of atypical Paleozoic 465 echinoderms: a quantitative survey of patterns of stylophoran disparity, diversity, and 466 geography. Paleobiology 32:483-510.

467 Ilyes RR., Elliott DK. 1994. New Early Devonian pteraspidids (Agnatha, Heterostraci) from 468 East-Central Nevada. Journal of Paleontology 68:878-892.

469 Lofgren AS, Plotnick RE, Wagner APJ. 2003. Morphological diversity of Carboniferous 470 arthropods and insights on disparity patterns through the Phanerozoic. Paleobiology 29:349$471 \quad 368$.

472 Marx FG, Fordyce RE. 2015. Baleen boom and bust: a synthesis of mysticete phylogeny, 473 diversity and disparity. Royal Society Open Science 2:140434. 
474 McGhee G.R. Jr 1995. Geometry of evolution in the biconvex Brachiopoda: morphologic effects

475 of mass extinction. Neues Jahrbuch fur Geologie und Palaontologie-Abhandlungen

476 197:357-382.

477

MacLeod N. 2002. Phylogenetic signals in morphometric data. 100-138. In MacLeod N., Forey P.L. (eds.). Morphology, Shape and Phylogeny. Taylor \& Francis Inc., New York, NY.

479

480

481

482

483

484

485

486

487

488

489

490

491

492

493

494

Mongiardino Koch N, Ceccarelli FS, Ojanguren-Affilastro AA, Ramírez MJ. 2017. Discrete and morphometric traits reveal contrasting patterns and processes in the macroevolutionary history of a clade of scorpions. Journal of evolutionary biology 30:814-825.

Pernègre VN. 2002. The genus Doryaspis White (Heterostraci) from the Lower Devonian of Vestspitsbergen, Svalbard. Journal of Vertebrate Paleontology 22:735-746.

Pernègre VN, Elliott DK 2008. Phylogeny of the Pteraspidiformes (Heterostraci), Silurian Devonian jawless vertebrates. Zoologica Scripta 37,391-403. DOI: 10.1111/j.14636409.2008.00333.x.

Pernègre VN, Goujet D. 2007. The Genus Gigantaspis Heintz, 1962 (Vertebrata, Heterostraci) from the Lower Devonian of Spitsbergen. Palaeontology 50,323-346. DOI: 10.1111/j.14754983.2007.00638.x.

Prentice KC, Ruta M, Benton MJ. 2011. Evolution of morphological disparity in pterosaurs. Journal of Systematic Palaeontology 9:337-353.

Randle E, Sansom RS. 2016. Exploring phylogenetic relationships of Pteraspidiformes heterostracans (stem- gnathostomes) using continuous and discrete characters. Journal of Systematic Palaeontology, DOI: 10.1080/14772019.2016.1208293. 
495 Randle E, Sansom RS. 2017a. Exploring phylogenetic relationships of Pteraspidiformes

496 heterostracans (stem-gnathostomes) using continuous and discrete characters. Journal of

497 Systematic Palaeontology 15(7):583-599.

498

499

500

501

502

503

504

505

506

507

508

509

510

511

512

513

514

515

516

Randle E, Sansom RS. 2017b. Phylogenetic relationships of the "higher heterostracans" (Heterostraci: Pteraspidiformes and Cyathaspididae), extinct jawless vertebrates. Zoological Journal of the Linnean Society 181(4):910-926.

Romano M. 2017a. Disparity vs. diversity in Stegosauria (Dinosauria, Ornithischia): cranial and post-cranial sub-dataset provide different signals. Historical Biology, DOI: 10.1080/08912963.2017.1397655.

Romano M. 2017b. Long bone scaling of caseid synapsids: a combined morphometric and cladistic approach. Lethaia 50(4):511-526, http://dx.doi.org/10.1111/let.12207.

Romano M, Citton P. 2015. Reliability of digit length impression as a character of tetrapod ichnotaxobase: considerations from the Carboniferous-Permian ichnogenus Ichniotherium. Geological Journal 50:827-838.

Romano M, Citton P. (2017). Crouching theropod at the seaside. Matching footprints with metatarsal impressions and theropod authopods: a morphometric approach. Geological Magazine 154(5):946-962.

Romano M, Brocklehurst N, Manni R, Nicosia U. 2018. Multiphase morphospace saturation in cyrtocrinid crinoids. Lethaia, DOI:10.1111/let.12276.

Romano M, Brocklehurst N, Fröbisch J. 2017. Discrete and continuous character-based disparity analyses converge to the same macroevolutionary signal: a case study from captorhinids. Scientific Reports 7(1):17531, DOI: 10.1038/s41598-017-17757-5. 
517 Ruta M. 2009. Patterns of morphological evolution in major groups of Palaeozoic

518 Temnospondyli (Amphibia: Tetrapoda). Special Papers in Palaeontology 81:91-120.

519 Ruta M, Angielczyk KD, Fröbisch J, Benton MJ. 2013. Decoupling of morphological disparity

520 and taxic diversity during the adaptive radiation of anomodont therapsids. Prooceding Royal

$521 \quad$ Society B 280:20131071.

522 Sansom RS. 2009. Endemicity and palaeobiogeography of the Osteostraci and Galeaspida: a test

523 of scenarios of gnathostome evolution. Palaeontology 52:1257-1273.

524 Sansom RS, Randle E, Donoghue PC. 2015. Discriminating signal from noise in the fossil record

525 of early vertebrates reveals cryptic evolutionary history. Proceedings of the Royal Society of

526 London B: Biological Sciences 282(1800):20142245.

527 Saunders WB, Work DM. 1996. Shell morphology and suture complexity in Upper

528 Carboniferous ammonoids. Paleobiology 22(2):189-218.

529 Saunders WB, Work DM. 1997. Evolution of shell morphology and suture complexity in

530 Paleozoic prolecanitids, the rootstock of Mesozoic ammonoids. Paleobiology 23(3):301$531 \quad 325$.

532 Scholz H, Hartman JH. 2007. Paleoenvironmental reconstruction of the Upper Cretaceous Hell

533 Creek Formation of the Williston Basin, Montana, USA: Implications from the quantitative 534 analysis of unionoid bivalve taxonomic diversity and morphologic disparity. Palaios 22:2453534.

536 Smith LH, Bunje PM. 1999: Morphologic diversity of inarticulate brachiopods through the 537 Phanerozoic. Paleobiology 25:396-408. 
538 Villier L, Eble GJ. 2004. Assessing the robustness of disparity estimates: the impact of

539 morphometric scheme, temporal scale, and taxonomic level in spatangoid echinoids.

540 Paleobiology 30:652-665.

541 Wagner PJ. 1995. Diversity patterns among early gastropods: contrasting taxonomic and 542 phylogenetic descriptions. Paleobiology 21:410-439.

543 Wagner PJ. 1997. Patterns of morphologic diversification among the Rostroconchia.

$544 \quad$ Paleobiology 23(1):115-150.

545 Whiteside JH, Ward PD. 2011. Ammonoid diversity and disparity track episodes of chaotic

$546 \quad$ carbon cycling during the early Mesozoic. Geology 39:99-102.

547 Wills MA, Briggs DEG, Fortey RA. 1994. Disparity as an evolutionary index: a comparison of

548 Cambrian and Recent arthropods. Paleobiology 20:93-131.

549 White, E. I. 1935. The ostracoderm Pteraspis Kner and the rela- tionships of the agnathous

550 vertebrates. Philosophical Trans- actions of the Royal Society of London, Series B, 225, $551 \quad 381-457$.

552

553 Figure captions

554 Figure 1. (A) Dorsal shield of Protopteraspis sartoki NMC.13869 (National Museum of Canada,

555 Ottawa, Canada) a Protopteraspididae Pteraspidiformes. (B) Ventral view of Errivaspis

556 waynensis P.17479 (Natural History Museum, London, UK) a Rhinopteraspididae

557 Pteraspidiformes. (C) Dorsal view of Cosmaspis transversa PF4924 (Field Museum,

558 Chicago, USA) a Protaspididae Pteraspidiformes. (D) Pteraspidiformes anatomy. (E)

559 Reconstruction cartoons of the main Pteraspidiformes groups and general morphologies. 
560 Scale bar-10mm. Rhinopteraspididae - Blieck 1981, Anchipteraspididae Elliott 1984, $561 \quad$ Protopteraspididae Blieck \& Tarrant 2001.

562 Figure 2. (A) Pteraspidiformes taxic diversity through time, (B) disparity of Pteraspidiformes

563 heterostracans using discrete characters (both total variance and sum of ranges), (C)

564 disparity of Pteraspidiformes heterostracans using continuous characters (both total variance 565 and sum of ranges).

566 Figure 3. Morphospace occupation through time in Pteraspidiformes heterostracans for the (A) 567 discrete characters, and (B) continuous characters.

568 Figure 4. Scatter plots of first two principal components and principal coordinates performed 569 respectively on (A) continuous characters (B) discrete characters. Taxonomic assignment 570 following Randle \& Sansom (2017a), with references to taxonomic groups in Figure 1. 


\section{Figure 1}

Headshield morphologies in stem gnathostomes pteraspidiformes heterostracans

(A) Dorsal shield of Protopteraspis sartoki NMC.13869 (National Museum of Canada, Ottawa, Canada) a Protopteraspididae Pteraspidiformes. (B) Ventral view of Errivaspis waynensis P.17479 (Natural History Museum, London, UK) a Rhinopteraspididae Pteraspidiformes. (C) Dorsal view of Cosmaspis transversa PF4924 (Field Museum, Chicago, USA) a Protaspididae Pteraspidiformes. (D) Pteraspidiformes anatomy. (E) Reconstruction cartoons of the main Pteraspidiformes groups and general morphologies. Scale bar - 10 mm. Rhinopteraspididae Blieck 1981, Anchipteraspididae Elliott 1984, Protopteraspididae Blieck \& Tarrant 2001. 


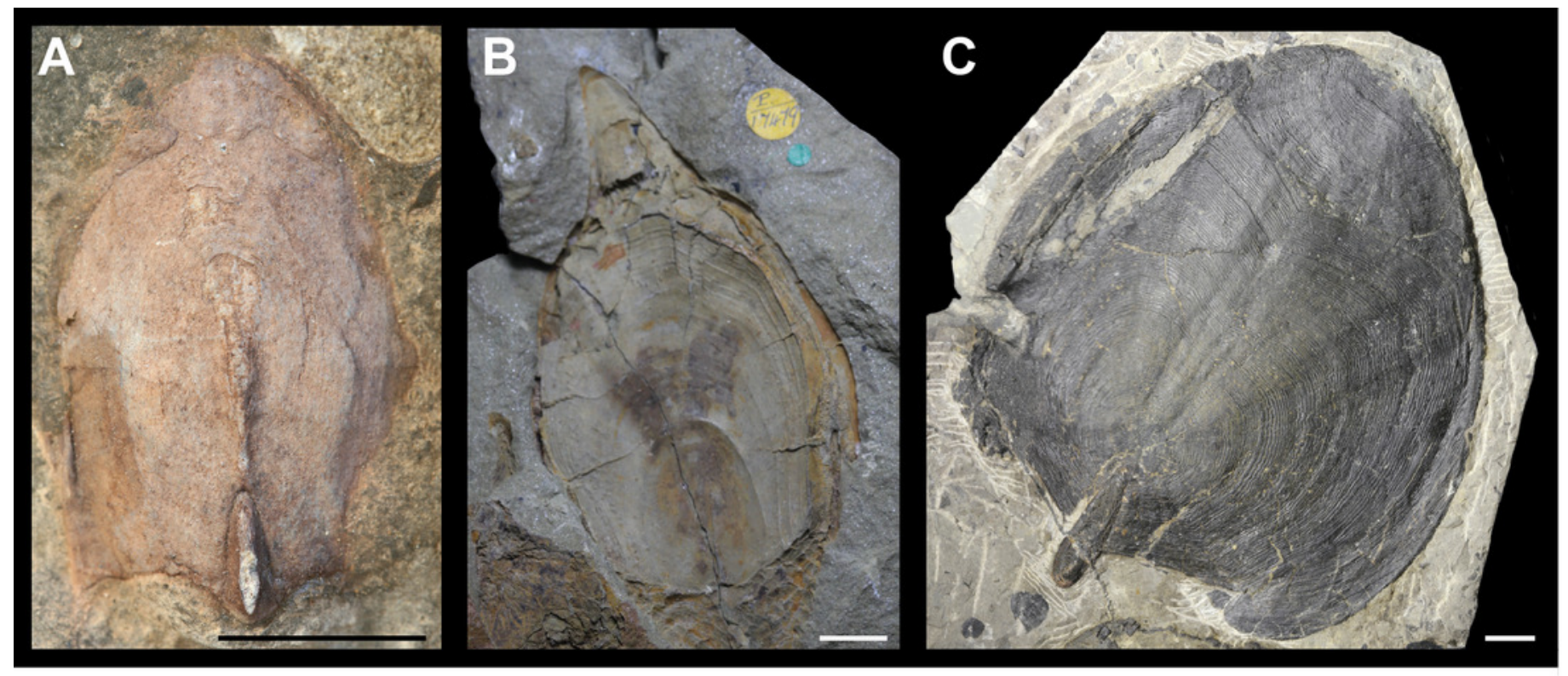

D

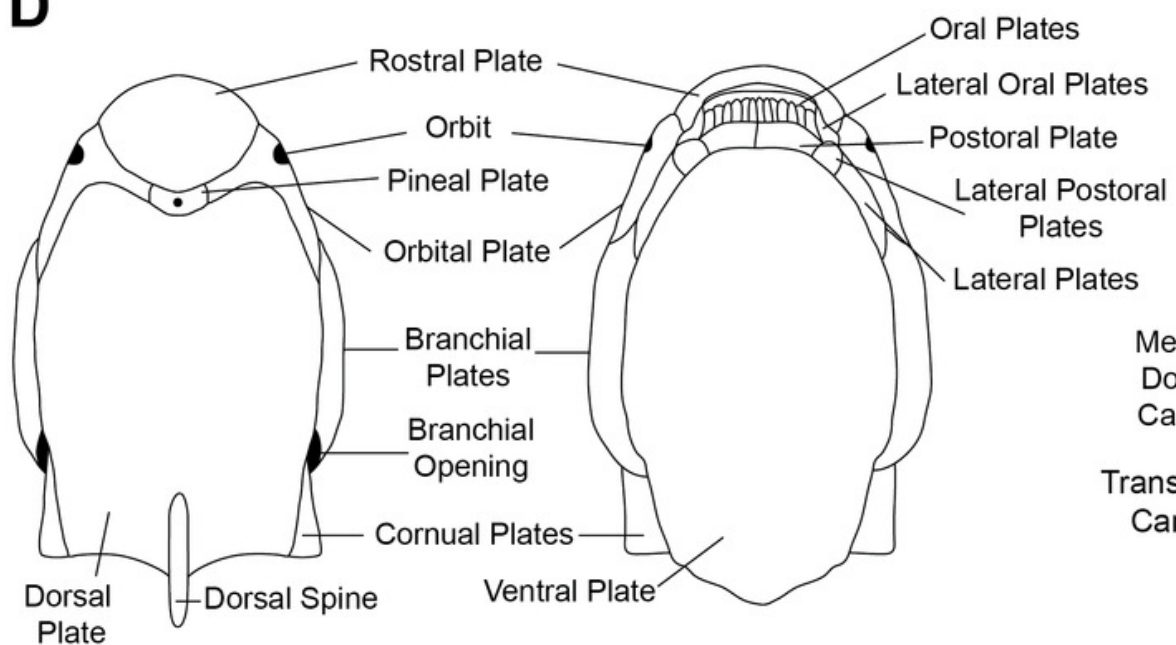



Psammosteidae

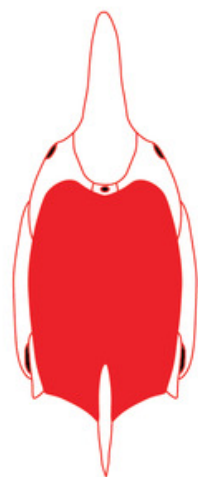

Rhinopteraspididae

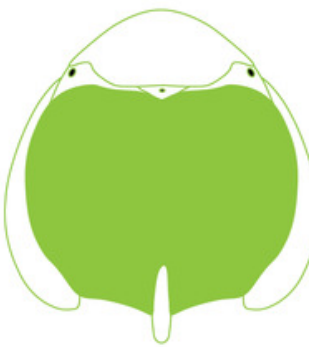

Protaspididae

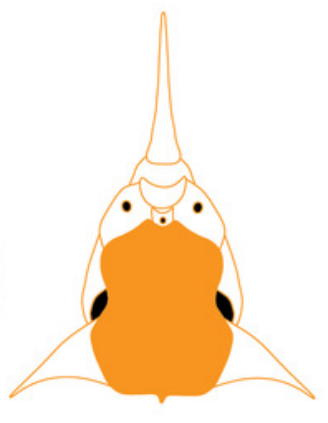

Doryaspidae
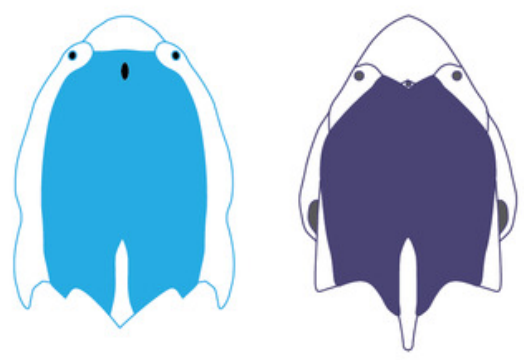

Anchipteraspididae
Supra Orbital Canals

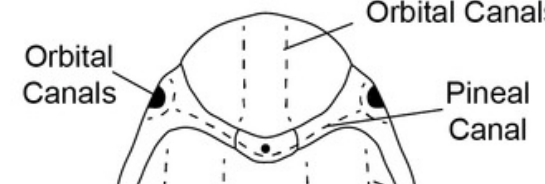

ateral

Canals

Median

Transverse

Canals

Canals

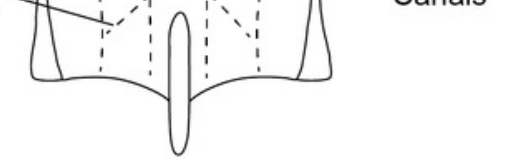




\section{Figure 2}

Disparity and diversiry trends in stem gnathostomes pteraspidiformes heterostracans

(A) Pteraspidiformes taxic diversity through time, (B) disparity of Pteraspidiformes

heterostracans using discrete characters (both total variance and sum of ranges), (C)

disparity of Pteraspidiformes heterostracans using continuous characters (both total variance and sum of ranges).

*Note: Auto Gamma Correction was used for the image. This only affects the reviewing manuscript. See original source image if needed for review. 


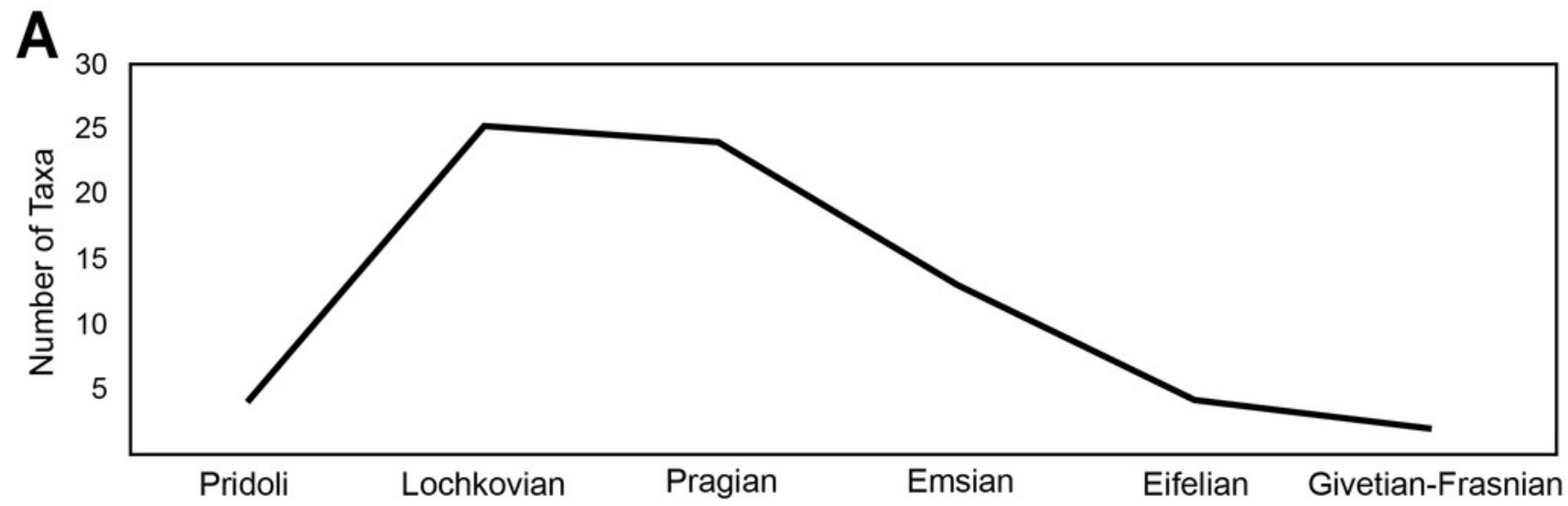

B Discrete Characters

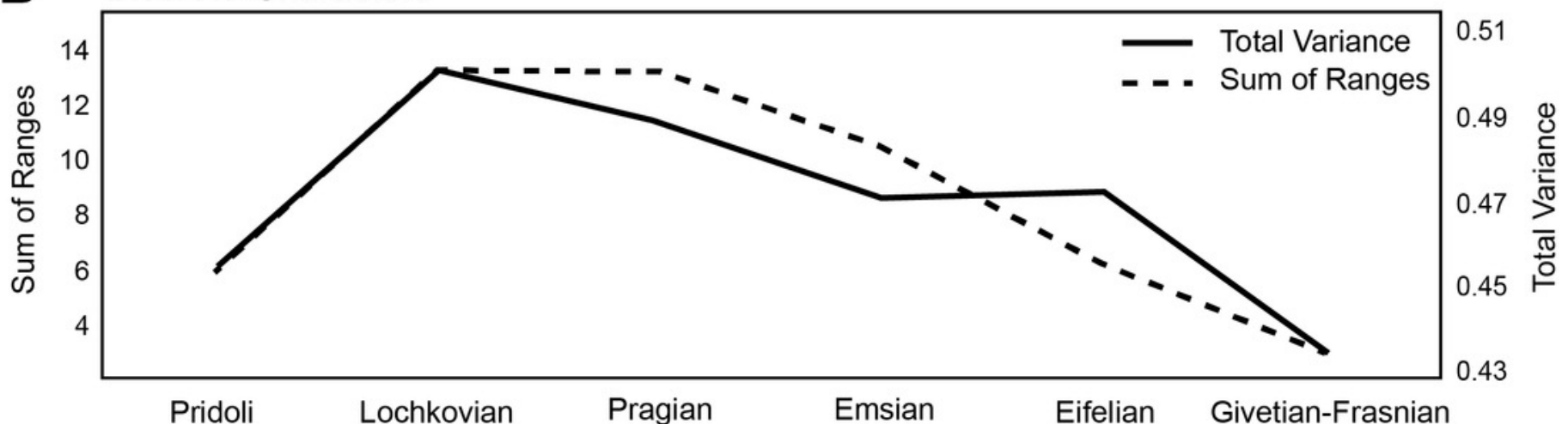

C Continuous Characters

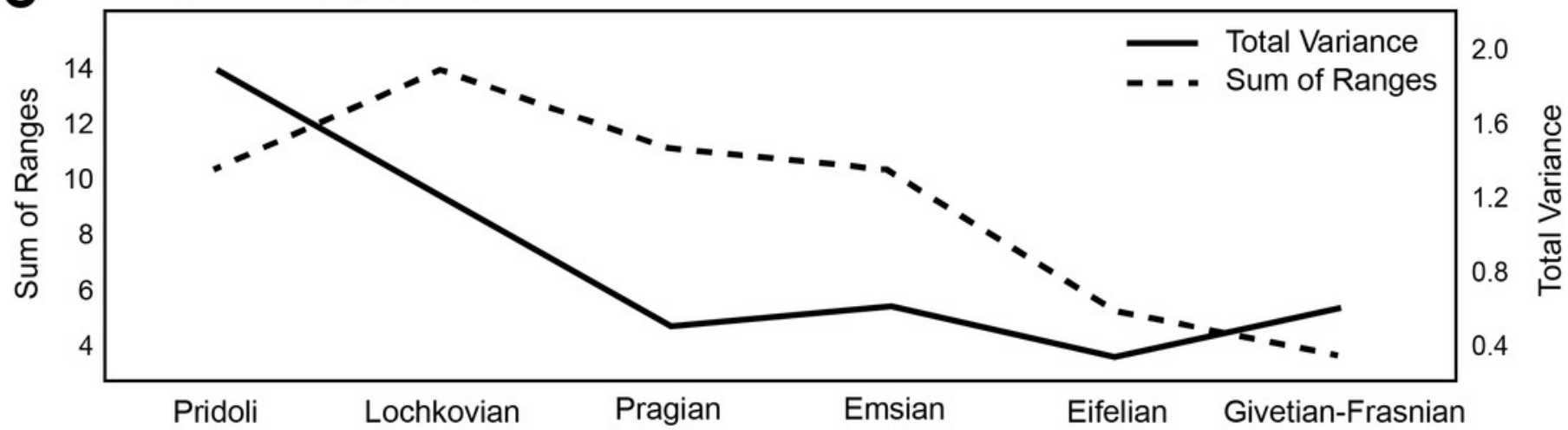




\section{Figure 3}

Morphospace occupation for the discrete characters and continuous characters through time in pteraspidiformes heterostracans

Morphospace occupation through time in Pteraspidiformes heterostracans for the (A) discrete-with-discretised characters, and (B) continuous characters. 
Time Bins A Discrete Characters

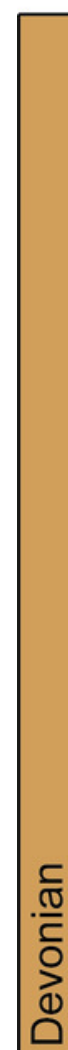
372.2

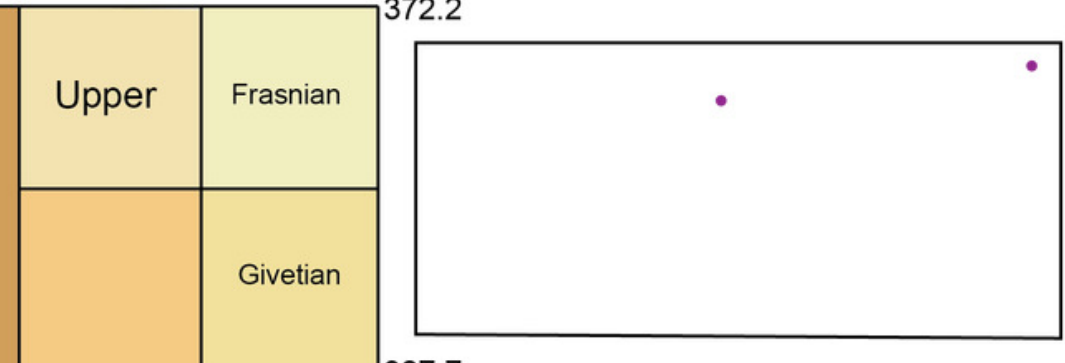

387.7

밈

393.3
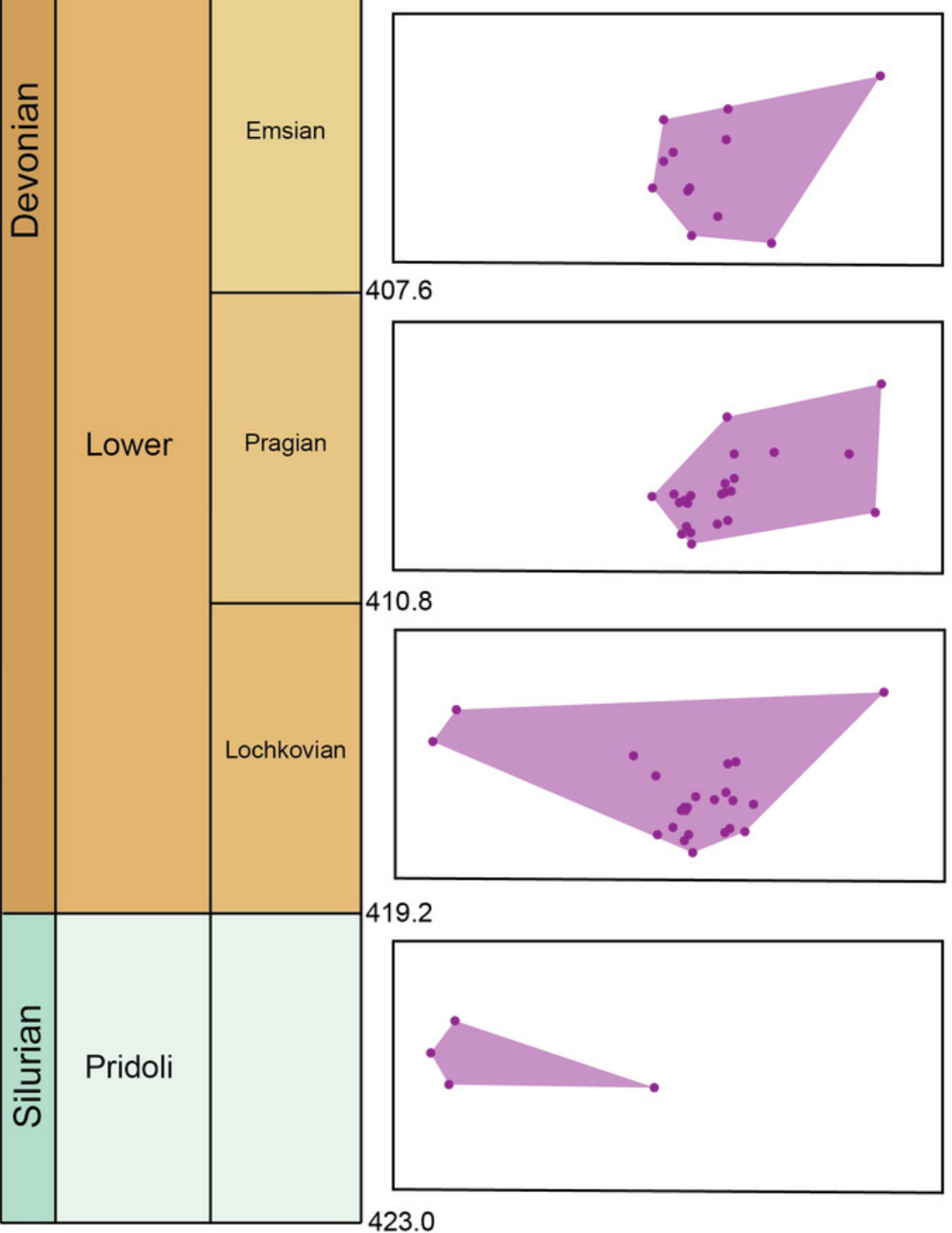
407.6

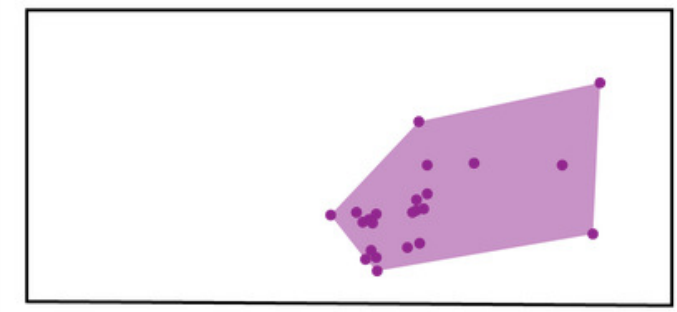
410.8

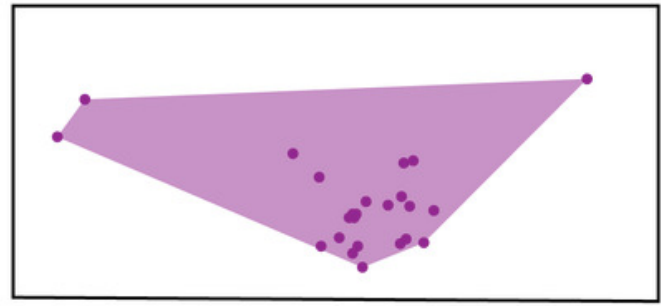

419.2

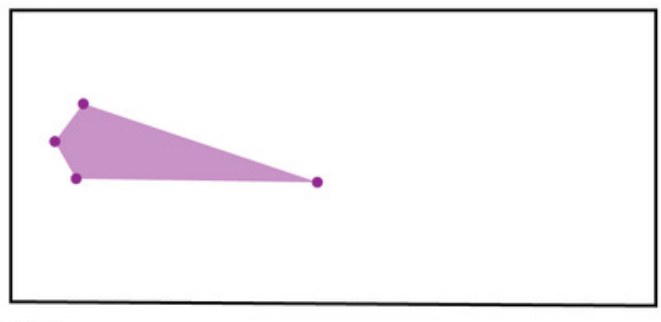

423.0

B

Continuous

Characters
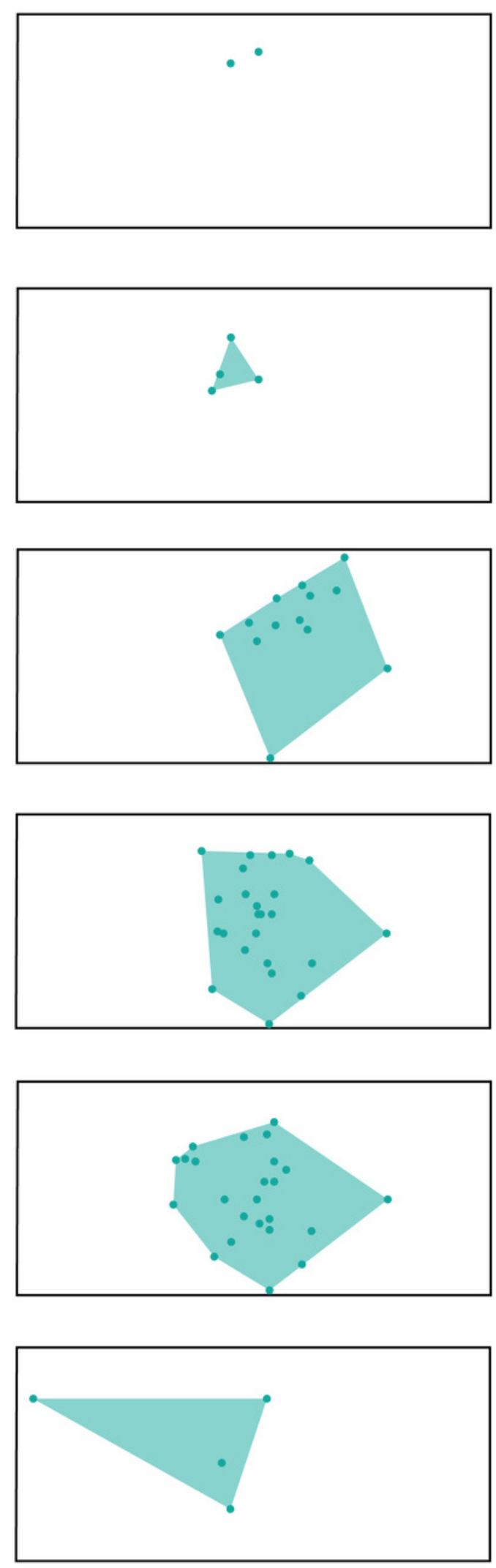
Figure 4

Morphospace exploration for discrete and continous characters in pteraspidiformes heterostracans

Scatter plots of first two principal components performed on continuous characters $(A)$ and first two principal coordinated on discrete characters (B). The group are named following Randle \& Sansom (2017a). 


\section{A Discrete-with-Discretised Characters}

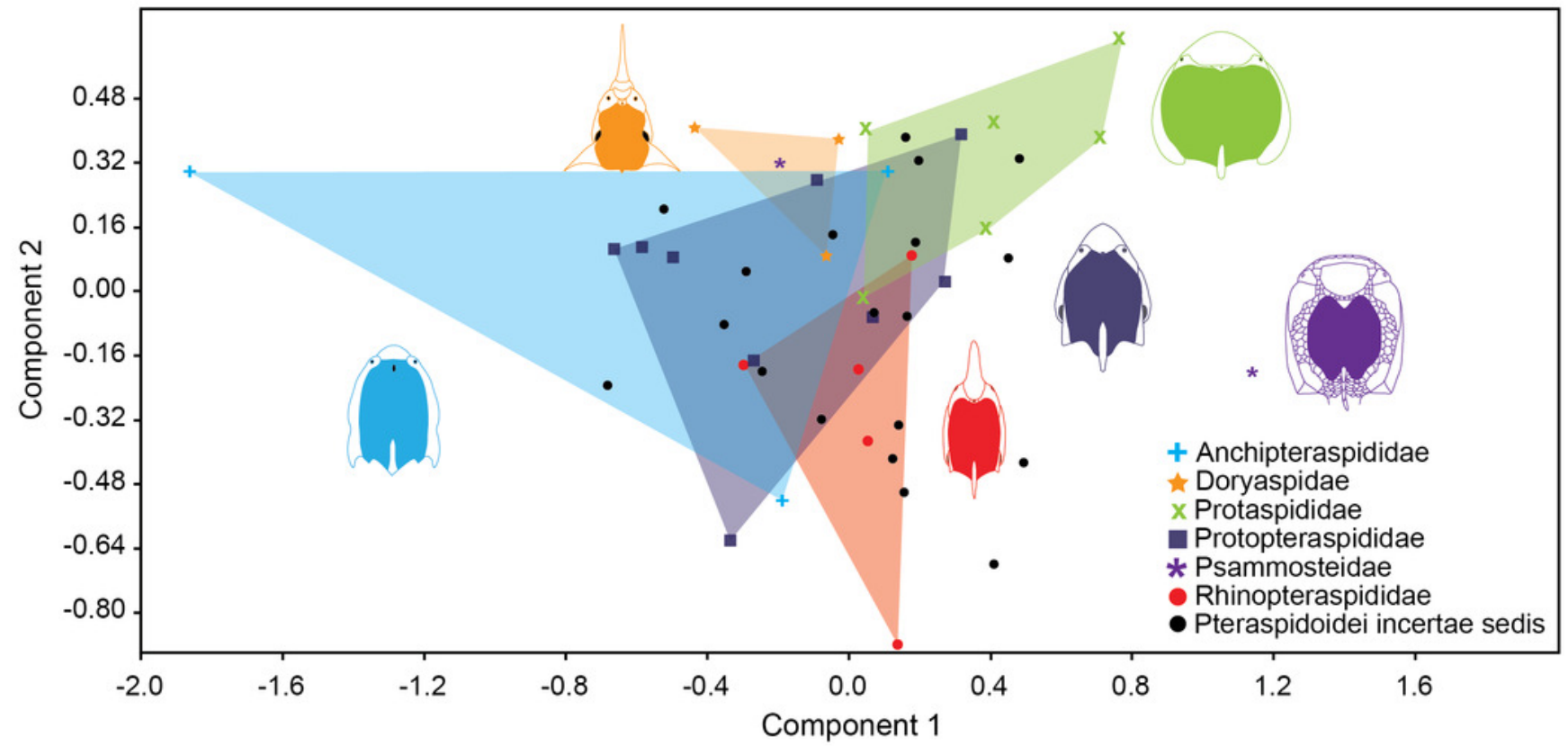

\section{B Continuous Characters}

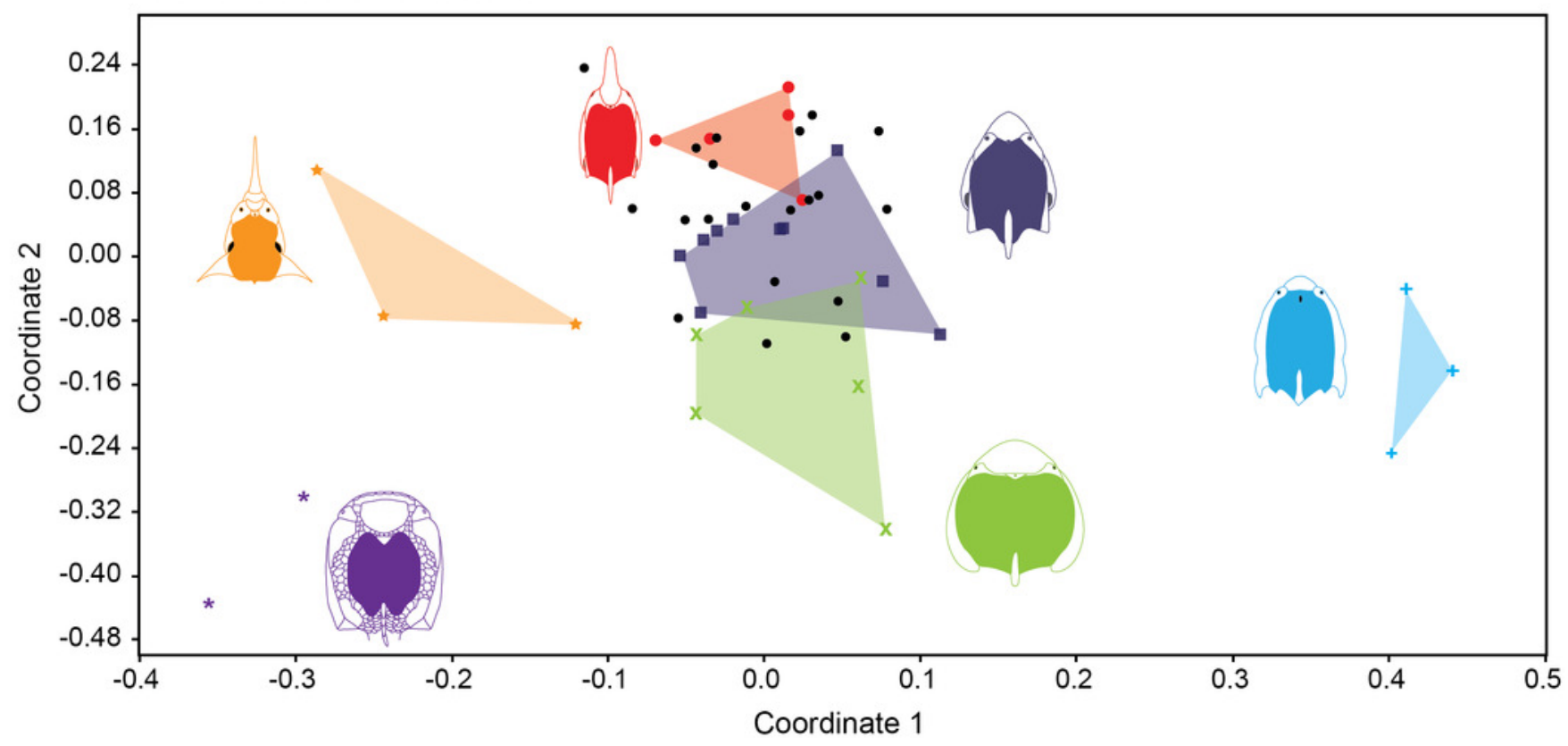

